\title{
WhatsApp Messenger as a Learning Tool: An Investigation of Pre-service Teachers' Learning without Instructor Presence
}

\author{
Ali A. Alenazi \\ Correspondence: Ali A. Alenazi, Department of Curriculum and Instruction, College of Education, Jazan University, \\ Jazan, Saudi Arabia.
}

Received: October 8, 2017

doi:10.11114/jets.v6i1.2684

\author{
Accepted: November 13, 2017 \\ Online Published: November 14, 2017 \\ URL: https://doi.org/10.11114/jets.v6i1.2684
}

\begin{abstract}
This study investigated the extent to which pre-service teachers can utilize WhatsApp Messenger to create an effective learning platform without instructor interference. Twenty-six male pre-service teachers created a WhatsApp group and interacted through it independently for nine weeks. Each pre-service teacher was required to share a minimum of two posts on a weekly basis, for eighteen posts in total. The pre-service teachers were given clear rules for participation that included a wide range of topics and the definition of an accepted post. The frequency of posts was recorded to determine the magnitude of participation. Focus group interviews were conducted to investigate reasons behind each pre-service teacher's magnitude of participation. The results of the study revealed that the participation rate of the entire group was unsatisfactory $(57 \%)$, with only six pre-service teachers meeting the minimum required number of posts. Interestingly, these six pre-service teachers created a small but unique norm of learning environment by regulating their own and other peers' performance as well. The reasons for the magnitude of participation, additional results, and implications of the study findings for educational settings are discussed.
\end{abstract}

Keywords: pre-service teachers, WhatsApp, learning tool, instructor presence

\section{Introduction}

Smartphones have become an integral part of our contemporary life. Youth, in particular, access the Internet to share a massive amount of media on a daily basis via instant messaging applications that can be downloaded on smartphones (Stornaiuolo \& Thomas, 2017). More than 1 billion people in over 180 countries use WhatsApp, one of the most popular instant messaging applications (Bouhnik \& Deshen, 2014; Ozcinar, Ekizoglu \& Kanbul, 2016). WhatsApp allows users to exchange texts, photos, audios, videos, documents, locations, voice calls, and video calls for free at any time and from anywhere in the world. One of its features is group chatting, where group members can share data without barriers or limits (WhatsApp Inc., 2017).

Research has found that integrating WhatsApp into higher education yielded desired learning as well as social benefits. For example, Plana et al. (2013) investigated the influence of the use of WhatsApp on students' reading skills in English as a foreign language with 95 participants at two universities in Catalonia over a 12-week period. The instructor(s) utilized content from the Quantum LEAP online learning environment and Macmillan's One Stop English website to design 37 tailored questions for their study (12 multiple choice, 12 fill-in-the-blank, 12 true/false, in addition to 1 open-ended question) whereas participants were sent three questions to answer through WhatsApp on a weekly basis. According to a student satisfaction survey conducted at the end of the study, approximately $91 \%$ of the students claimed that their participation in the project had increased their motivation toward reading in English. They also experienced a positive impact on their reading habits, which resulted in more regularity and confidence.

Similarly, Amry (2014) examined the effect of WhatsApp on the achievement and attitudes of 15 female college students who studied one unit out of a six-unit media education course through WhatsApp (i.e., experimental group) compared to another group of 15 female students who studied the same unit through face-to-face learning approach in the classroom (i.e., control group). The instructor provided and managed all the learning activities in the WhatsApp group during the research period. The study found differences at the 0.05 alpha level in favor of the experimental group regarding the achievement and attitudes toward the learning approach. The experimental group scored higher on the achievement test, as the students believed that WhatsApp made learning easier through knowledge sharing.

Bansal and Joshi (2014) investigated the perception of 37 pre-service teachers - 32 females and 5 males — on the use of 
WhatsApp after 40 days of communication between them and their instructor. The instructor provided messages regarding teaching practices, classroom management, participants' inquiries or problems, and administrative updates. According to a student experience survey conducted at the end of the study, $56 \%$ of the participants agreed that learning through WhatsApp was very interesting and offered educational benefits, $81 \%-82 \%$ claimed that their social interactivity with their peers and teacher had increased and they learned more collaboratively, and $76 \%$ had favorable attitudes toward WhatsApp as a learning tool.

The representative sample of studies discussed above provided empirical evidence that integrating WhatsApp into higher education yielded desired learning as well as social benefits. The common factor in all these studies was instructor presence. The instructor played a central role in the WhatsApp learning environment that included, but was not limited to, managing the learning process, providing feedback, and encouraging participation. Given the enormous amount of time students independently spend on WhatsApp on a daily basis, the question is whether they are able to learn with no interference from the instructor. Little is known about the extent students are able to utilize WhatsApp independently to improve their own learning. This study aims to investigate this matter among a sample of pre-service teachers from a college of education in Saudi Arabia.

The use of social media in Saudi Arabia is increasingly popular, mostly due to the low average age of its population. According to Statista.com (2017), 49\% of the 31.74 million people in Saudi Arabia were active WhatsApp users in 2016. An earlier study in 2015 conducted on a representative sample of 3000 participants (1883 males and 1117 females; 1145 participants were aged 20-29) by the Communications and Information Technology Commission in Saudi Arabia revealed that WhatsApp was the top the social media application used compared to other popular applications (e.g., Facebook, Twitter, and Instagram). The study also found that $43 \%$ of the participants claimed that they spend at least two hours daily on social networking sites. In an education class I teach, the pre-service teachers reported that they spend at least two hours daily on WhatsApp alone. Keeping in mind such substantial time spent on WhatsApp daily, the purpose of the present study was to investigate the extent to which these pre-service teachers can utilize WhatsApp independently to create an effective learning platform.

\section{Research Question}

To what extent do pre-service teachers utilize WhatsApp independently to create an effective learning platform?

\section{Methodology}

\subsection{Sample}

The sample of the current study included male pre-service elementary school teachers from a male college of education in Saudi Arabia. These pre-service teachers were enrolled in a three-hour general education course designed to help deepen their understanding of the principles of curriculum and instruction. Of the 28 pre-service teachers who enrolled in the course, 26 agreed to participate voluntarily in the study, and they were informed that they had the right to withdraw from the study at any time, with no consequences whatsoever. The remaining two pre-service teachers did not wish to participate and thus were given alternative assignments to complete.

\subsection{Procedures}

At the beginning of the semester, the participants were clearly informed of the five main elements of the study. First, the purpose of the study was to investigate the extent to which pre-service teachers utilize WhatsApp independently to create an effective learning platform. Participants were asked to create a WhatsApp group and share academic information of their choice related to the course within the group during the semester. Second, the duration of the study was 9 weeks. Third, a focus group interview would be conducted after the study. Fourth, the requirements were a smartphone with the WhatsApp application downloaded on it and an Internet connection. Fifth, the rules of the study were as follows: 1) each participant was required individually to create a minimum of two posts per week (18 posts in 9 weeks) about a topic of choice or another participant's topic; 2) the topics could be selected from the content of the required book, readings, projects, quizzes, exams, or any other related course activity; 3) participants received $1 / 2$ point for each post, 1 point for the two posts per week, 9 points in 9 weeks, covering $9 \%$ of the total course grade; 4) the posts had to be beneficial in order to be accepted and receive the allocated grade, where a beneficial post was defined as a piece of new information (never been posted in the group by any other participant) that added value to the class learning environment and an unbeneficial post would be posts of communication (e.g., the mid-term exam will be next Monday) or confirmations (e.g., yes, the answer is correct); and 5) the instructor would not interfere in the group activity in any way in order to serve the purpose of the study. The instructor's role was restricted to ensuring that the group was created and all participants were added plus the instructor; continuously monitoring, analyzing, and grading the participants' posts in the group; and providing each participant with a grade at the beginning of every week. 


\subsection{Data Collection and Data Analysis}

The study involved a mixed method approach, which combined quantitative and qualitative data (Johnson \& Onwuegbuzie, 2004). The quantitative data were collected from the WhatsApp group participation. A table of three main columns was created to record each participant's frequency and type of posts. The first column (i.e., participant) included the participant's name. The second column (i.e., post status) was divided into two sub-columns: beneficial and unbeneficial. The third column (i.e., post type) included five sub-columns: text, photo, video, voice message, and document. Each participant's posts were evaluated and then recorded under the appropriate spot in the table on a weekly basis. At the end of every week, all numbers were calculated. At the end of the study, all numbers from the weekly results were totaled to determine the final number of beneficial and unbeneficial posts as well as the final number of each post type. The quantitative data were analyzed using descriptive statistics in order to understand the magnitude of participation.

The qualitative data collected from the focus group interviews and the WhatsApp group posts. For the interviews, the participants were divided into three groups based on their magnitude of participation in the WhatsApp group at the end of the study. The first group, who met the minimum required number of beneficial posts (i.e., 18), had 6 members. The second and third groups, who failed to meet the minimum required number of beneficial posts, each had 10 members. Each focus group interview lasted approximately 50 minutes and was recorded upon the participants' consent. During the focus group interviews, each group was asked to justify the magnitude of their participation. Regarding the WhatsApp group posts, posts found to be related to participants' justification were collected. The raw data collected were analyzed using a thematic content analysis and then interpreted to understand the reasons behind the magnitude of participation.

\section{Results}

Table 1 presents the final results of the posts created by all participants during the study. Each participant was required to create individually a minimum of two beneficial posts per week (i.e., 18 posts in 9 weeks). Thus, the entire group of participants was required to collectively create a total of at least 468 beneficial posts. The results showed that they produced 1022 posts total: 371 beneficial posts and 651 unbeneficial posts.

Table 1. Summary of posts created by the entire group

\begin{tabular}{llll}
\hline Post Type & Total Count & Beneficial & Unbeneficial \\
\hline Texts & 745 & 131 & 614 \\
Photos & 268 & 237 & 29 \\
Videos & 1 & 1 & 0 \\
Voice Messages & 5 & 1 & 4 \\
Documents & 3 & 1 & 2 \\
Total & 1022 & 371 & 651 \\
\hline
\end{tabular}

Table 2 represents the breakdown of the 371 beneficial posts per participant. As the table indicates, 3 participants (12\%) did not produce any beneficial posts, 17 participants (65\%) produced fewer than 18 beneficial posts, and only 6 participants (23\%) produced 18 beneficial posts or more. The latter 6 participants produced 105 extra beneficial posts. Thus, the actual number of beneficial posts is $371-105=266$, which represents a participation rate of $57 \%$ of the collective minimum number required of 468 beneficial posts. 
Table 2. Details of beneficial posts per participant

\begin{tabular}{|c|c|c|c|c|}
\hline Participant & $\begin{array}{l}\text { \# Of required } \\
\text { beneficial posts }\end{array}$ & $\begin{array}{l}\text { \# Of extra } \\
\text { beneficial posts }\end{array}$ & $\begin{array}{l}\text { Range of required } \\
\text { beneficial posts }\end{array}$ & \# Of participants \\
\hline 1 & 0 & 0 & \multirow{3}{*}{ Zero } & \multirow{3}{*}{3} \\
\hline 2 & 0 & 0 & & \\
\hline 3 & 0 & 0 & & \\
\hline 4 & 2 & 0 & \multirow{17}{*}{$\begin{array}{l}1 \text { to less than } 18 \\
\text { posts }\end{array}$} & \multirow{17}{*}{17} \\
\hline 5 & 2 & 0 & & \\
\hline 6 & 2 & 0 & & \\
\hline 7 & 3 & 0 & & \\
\hline 8 & 6 & 0 & & \\
\hline 9 & 8 & 0 & & \\
\hline 10 & 8 & 0 & & \\
\hline 11 & 8 & 0 & & \\
\hline 12 & 10 & 0 & & \\
\hline 13 & 10 & 0 & & \\
\hline 14 & 10 & 0 & & \\
\hline 15 & 12 & 0 & & \\
\hline 16 & 14 & 0 & & \\
\hline 17 & 14 & 0 & & \\
\hline 18 & 15 & 0 & & \\
\hline 19 & 17 & 0 & & \\
\hline 20 & 17 & 0 & & \\
\hline 21 & 18 & 2 & \multirow{6}{*}{18 posts or more } & \multirow{6}{*}{6} \\
\hline 22 & 18 & 3 & & \\
\hline 23 & 18 & 8 & & \\
\hline 24 & 18 & 17 & & \\
\hline 25 & 18 & 36 & & \\
\hline \multirow[t]{2}{*}{26} & 18 & 39 & & \\
\hline & 266 & 105 & & \\
\hline Total & 371 & & & 26 \\
\hline
\end{tabular}

4.1 Participants Did Not Meet Minimum Participation Requirements (20)

The analysis of the focus group interview answers revealed certain commonalties among the 20 participants who did not meet the requirement for the minimum number of posts. Participants identified three minor reasons and a major one regarding the unsatisfactory magnitude of their participation.

\subsubsection{Minor Reasons}

\subsubsection{Untypical Usage of WhatsApp}

None of the participants had previously used WhatsApp as a learning platform within their courses. All claimed that, for them, WhatsApp was nothing more than a communication tool for staying up-to-date with their peers on new events and sharing information, but with no obligation:

I have a WhatsApp group for almost every class, but I only use it to communicate with my classmates. We share information about the course... For example, if I miss a class one day, I post a question in the group and my classmates will provide me with the topics discussed, materials, homework assigned that day, and/or updates if any... This was my first time joining a WhatsApp group to participate. It felt different because my participation was evaluated and graded.

\subsubsection{Negative Peer Pressure}

Negative peer pressure was evident in participants' statements as some chose to adopt the attitude of their passive peers:

I felt that not everyone was serious. Not everyone was participating regularly, and this affected my participation negatively... I did not want to lose the grade points, so I tried to share posts weekly, but I felt less motivated since my close friends were often not active in the group.

\subsubsection{Struggles/Issues with Certain Types of Posts}

Although participants were very familiar with the use of WhatsApp, some encountered issues with certain types of posts: 
I use voice messages with my family and close friends only... I did not feel comfortable sending a voice message in the class group... I never sent a voice message; I think I am a private person, so I prefer sending texts or photos (Privacy)... Sending a long piece of information through a voice message is easier for me than writing it as a text; however, I always needed a quiet spot to be able to send/record a voice message, which made me less interested in voice messages... I think listening to a voice message takes longer than reading a text or scanning a photo; thus, I prefer reading and sending texts or photos (Features)... I could not find the type of videos I was looking for... there were not enough videos about the topic I chose (Availability)... There was plenty of information in the form of documents, but I do not know how to send a document. Since I was not required to participate using a certain type of message, I mostly posted texts and photos. I prefer them because they are easy to create or find (Lack of knowledge).

These statements also shed light on the big difference between the number of text messages (745) and photo messages (268) compared to the other types of messages — videos (1), voice messages (5), and documents (3) —as seen in Table 1. One reason for this result is that the nature of the conversation often encourages participants to respond in texts. Another possible reason is that texts and photos are easier to create; an individual can type a text or take a shot of a page in a short time and send it immediately.

\subsubsection{Major Reason: No Instructor Presence}

The participants expressed dependence on the instructor. This dependence shows a lack of self-regulation skills, as they were unable to take control of their own learning. They still believed that the instructor was the focus of learning whereas students were supposed to exert the minimum possible effect on the environment work:

The participation in the WhatsApp group is exactly similar to the scenario where the instructor assigns us an activity and leaves the classroom. Not everyone would take it serious and do their part... I felt less obligated to participate without any interference from the instructor... The rules were very clear and helpful, but I still believe that the instructor's management is always essential in the learning environment... I am used to working under instructor supervision all the time... No specific topic was announced regularly. I think the instructor should tell us what to discuss every week... I do not trust my classmates' answers. I need the instructor's feedback to confirm information provided by my classmate and that my answers are correct.

\subsection{Participants Met Minimum Participation Requirements (6)}

The 6 participants who individually created the minimum number of posts required or more revealed certain explanations regarding the high magnitude of their participation. They all agreed that finding beneficial information to share was challenging at times, but creating only two posts per week was not difficult. As one participant stated, "I posted new information twice a week, but I also found myself creating plenty of extra posts by responding to my peers' questions about my own posts and others' as well. There were lots of inquiries. It was interesting though.” Another participant claimed that "it was obvious that some students were not participating regularly... so I felt obligated to post a reminder a few times." Such a reminder was found in the following WhatsApp conversation: "reminder guys: each one needs to keep posting at least two new and beneficial posts every week."

A third participant indicated that there was a noticeable repetition in the conversation: "I realized that the same information was posted by different students... I mentioned that in the group conversation." He posted a message to a classmate, saying that "this is a useful piece of information; however, it was already posted by Mo on Tuesday, March 14. Check it out. You need to post a new one ASAP in order to get the point." Different participants reacted to the repetition issue by suggesting strategies to avoid it. For example, they wrote, "before sending your post, please read the previous posts and make sure what you are sharing is not a repetition...the range of topics is wide, just take a glance of the topics already discussed... and select a new one."

A fourth participant reflected on his peers' answers and provided corrections at times. In one example, he noted that "the answer is wrong. Look at the correct answer in the attached photo below." Other times, he provided advice on where to find the answer, such as "your answer is incomplete. Look at page 255 in the book."

It was clear that the 6 participants were very active in the WhatsApp group. They not only provided lots of new information, but also communicated and confirmed peers' answers, which were considered unbeneficial posts according to the study rules. This inference is consistent with the results presented in Table 3, comparing the number of beneficial and unbeneficial posts for each participant. The table shows that two groups produced the highest number of unbeneficial posts: participants with the lowest number of beneficial posts, whose unbeneficial posts were mostly inquiries about their peers' posts, and the 6 participants who had the highest number of beneficial posts, whose unbeneficial posts were mostly communication and confirmation posts with no new information added. 
Table 3. Comparison of beneficial and unbeneficial posts per participant

\begin{tabular}{|c|c|c|}
\hline Participant & \# Of beneficial posts & \# Of unbeneficial posts \\
\hline 1 & 0 & 0 \\
\hline 2 & 0 & 21 \\
\hline 3 & 0 & 36 \\
\hline 4 & 2 & 39 \\
\hline 5 & 2 & 27 \\
\hline 6 & 2 & 2 \\
\hline 7 & 3 & 31 \\
\hline 8 & 6 & 25 \\
\hline 9 & 8 & 15 \\
\hline 10 & 8 & 0 \\
\hline 11 & 8 & 3 \\
\hline 12 & 10 & 6 \\
\hline 13 & 10 & 13 \\
\hline 14 & 10 & 15 \\
\hline 15 & 12 & 11 \\
\hline 16 & 14 & 10 \\
\hline 17 & 14 & 21 \\
\hline 18 & 15 & 11 \\
\hline 19 & 17 & 2 \\
\hline 20 & 17 & 9 \\
\hline 21 & $20(18+2)$ & 17 \\
\hline 22 & $21(18+3)$ & 55 \\
\hline 23 & $26(18+8)$ & 43 \\
\hline 24 & $35(18+17)$ & 70 \\
\hline 25 & $54(18+36)$ & 77 \\
\hline 26 & $57(18+39)$ & 92 \\
\hline Total & 371 & 651 \\
\hline
\end{tabular}

\section{Discussion and Conclusion}

This study was conducted to better understand to what extent pre-service teachers utilize WhatsApp independently to create an effective learning platform. It was found that integrating the use of WhatsApp in the learning environment does not automatically enhance pre-service teachers' learning per se. Rather, WhatsApp needs to be used in certain conditions in order to yield the desired outcomes.

In the present study, the pre-service teachers participated independently in a WhatsApp group, in which they were collectively required to create 468 beneficial posts in 9 weeks (i.e., 18 posts per participant). The results showed that the cumulative rate of beneficial posts created by all participants was $57 \%$, with only $23 \%$ of the participants (i.e., 6 ) creating the minimum individual number of beneficial posts required or more. This rate is considered low.

From the analysis of the results, the study provided evidence that participants did not take their participation seriously for several reasons - most notably, the absence of instructor presence. The participants were asked to participate individually without interference from the instructor after they were provided with a clear set of rules that included a wide range of topics to select from for participation, the definition of a beneficial post, the required number of beneficial posts required per week, and the grade points awarded for each beneficial post. Although all participants indicated these rules were helpful, most believed the rules were insufficient to encourage participation without the instructor's presence. They believed that the instructor's presence during the participation process would have helped 
improve the quantity and quality of their participation. They recommended that instructor presence may include, but not be limited to, assigning a specific topic to discuss weekly, providing feedback on their answers, and managing the discussion. Clearly, this result would not be a radical departure from what previous studies have shown regarding the significant influence of the instructor on the WhatsApp learning environment (Plana et al., 2013; Amry, 2014).

Despite the low rate of beneficial posts, the present study detected a small but unique norm of participation amongst two groups of participants: one group that had the highest frequency of beneficial posts and a second group that had the lowest frequency of beneficial posts. The former group created a rich learning environment as they provided plenty of new information about topics within the predetermined range. The latter group created plenty of inquiries about the information, which encouraged the first group to interact. Thus, the first group provided feedback on inquiries and injected extra information to improve their peers' performance.

The former group also utilized their self-regulation skills to monitor and reflect on peers' performance. Monitoring was explicit in reactions to repeated information, such as "this is a useful piece of information; however, it was already posted by Mo on Tuesday, March $14 \ldots$ before sending your post, please read the previous posts and make sure what you are sharing it is not a repetition." Reflection was clear in statements such as "the answer is wrong. Look at the correct answer in the attached photo below" or "your answer is incomplete. Look at page 255 in the book." In this norm of participation, the first group extended their self-regulation where "[a pre-service teacher] regulates his/her own learning with no apparent intentions to influence others [pre-service teachers'] cognitions, emotions and behaviors" (Grau \& Whitebread, 2012, p. 411) to co-regulation where "one member of a group who has more knowledge and skills provides scaffolding support for another" (Hayes, Smith, \& Shea, 2015, p. 5). Ultimately, although this unique norm of participation was limited in volume, it benefited the entire class in one way or another, without exception - even those who did not produce a single post.

While supporting previous findings that show WhatsApp can provide students with opportunities to engage with each other in thoughtful learning (Bansal \& Joshi, 2014), this finding is a clear indication that effective self-regulation is an important factor for effective independent learning through WhatsApp. Accordingly, pre-service teachers should be given the opportunity to exercise self-regulation. One effective way to develop self-regulation skills is to provide related learning experiences where pre-service teachers can exercise taking control of their own learning as they learn how to plan, monitor, and reflect on their own learning (Randi, 2004). Although developing effective self-regulation skills could require extensive time and effort, they are worth the effort. Self-regulation is essential in the education process as a primary goal of education is to develop lifelong learning skills that will allow learners to function in their chosen workplace (Zimmerman, 2002).

Given that WhatsApp continues to be the most popular application used on a regular basis among college students in Saudi Arabia, educators should investigate all related factors that could help make it an effective tool in enhancing pre-service teachers' learning. The current study confirmed the results of past research-namely, that instructor presence during the learning activities through social media plays an important role in student achievement. Junco, Elavsky and Heiberger (2012) demonstrated that "faculty who are more engaged on the platform with their students will see greater gains in academic outcomes (p. 11)." Yet the present study also provided evidence that pre-service teachers with adequate self-regulation skills can learn independently through WhatsApp while helping their peers learn. Combining these two types of learning could increase the learning and social benefits of WhatsApp for pre-service teachers. The findings of this study may be used to assist in the development and implementation of instructional methods to prepare teacher programs that encourage the building of indispensable skills, such as self-regulation skills.

A limitation of the present study is its use of a small sample from one university, which limits the findings' generalizability to other populations. Another limitation was that no females participated in the study; only a small male sample was used. The study may have yielded different results if the sample was larger and included females.

\section{References}

Amry, A. (2014). The impact of WhatsApp mobile social learning on the achievement and attitudes of female students compared with face to face learning in the classroom. European Scientific Journal, 10(22), 116-136.

Bansal, D., \& Joshi, T. (2014). A Study of Students Experiences of WhatsApp Mobile Learning. Global Journal of Human-Social Science Research, 14(4).

Bouhnik, D., \& Deshen, M. (2014). WhatsApp goes to school: Mobile instant messaging between teachers and students. Journal of Information Technology Education: Research, 13, 217-231. https://doi.org/10.28945/2051

Communications and Information Technology Commission. (2015). Individuals Report ICT Survey Results. Riyadh, CITC.

Grau, V., \& Whitebread, D. (2012). Self and social regulation of learning during collaborative activities in the classroom: 
The interplay of individual and group cognition. Learning and Instruction, 22(6), 1-12. https://doi.org/10.1016/j.learninstruc.2012.03.003

Hayes, S., Smith, S., \& Shea, P. (2015). Expanding learning presence to account for the direction of regulative intent: Self-, co- and shared regulation in online learning. Journal of Online Learning, 19(3), 1-19.

Johnson, B., \& Onwuegbuzie, A. (2004). Mixed methods research: A research paradigm whose time has come. Educational Researcher, 33(7), 14-26. https://doi.org/10.3102/0013189X033007014

Junco, R., Elavsky, C., \& Heiberger, G. (2012). Putting twitter to the test: assessing outcomes for student collaboration, engagement and success. British Journal of Educational Technology, 44, 273-287. https://doi.org/10.1111/j.1467-8535.2012.01284.x

Ozcinar, Z., Ekizoglu, N., \& Kanbul, S. (2016). A study on developing a scale for determining the educational usage of mobile communication apps. Journal of Universal Computer Science, 22(1), 146-158.

Plana, M., Gibert, M., Triana, I., Gimeno, A., Appel, C., \& Hopkins, J. (2013). Improving learners' reading skills through instant short messages: a sample study using WhatsApp. Paper presented at World-CALL 2013-CALL: Sustainability and Computer-Assisted Language Learning, 80-84.

Randi, J. (2004). Teachers as Self-Regulated Learners. Teachers College Record, 106, 1825-1853. https://doi.org/10.1111/j.1467-9620.2004.00407.x

Statista Inc,. (2017). Share of population in selected countries who are active WhatsApp users as of 4th quarter. Retrieved from https://www.statista.com/statistics/291540/mobile-internet-user-whatsapp/

Stornaiuolo, A., \& Thomas, E. (2017). Disrupting educational inequalities through youth digital activism. Review of Research in Education, 41.

WhatsApp Inc,. (2107). WhatsApp features. Retrieved from https://www.whatsapp.com/features/

Zimmerman, B. (2002). Becoming a self-regulated learner: An overview. Theory Into Practice, 41(2), 64-71. https://doi.org/10.1207/s15430421tip4102_2

\section{Copyrights}

Copyright for this article is retained by the author(s), with first publication rights granted to the journal.

This is an open-access article distributed under the terms and conditions of the Creative Commons Attribution license which permits unrestricted use, distribution, and reproduction in any medium, provided the original work is properly cited. 